\title{
Comparison by simulation of PEGASIS and IEEPB routing protocols
}

\author{
Samah Alnajdi, Fuad Bajaber \\ Department of Information Technology, Faculty of Computing and Information Technology, \\ King Abdulaziz University, Kingdom of Saudi Arabia
}

\begin{tabular}{l} 
Article Info \\
\hline Article history: \\
Received Mar 1, 2019 \\
Revised Jul 22, 2019 \\
Accepted Jul 28, 2019 \\
\hline Keywords: \\
Energy consumption \\
Hierarchical routing protocols \\
Network lifetime \\
Simulation \\
Wireless sensor networks
\end{tabular}

\begin{abstract}
As the applications of wireless sensor networks (WSNs) became widely used throughout the years the importance of advanced sensor networks techniques increased as well. One of the main techniques used in WSNs is hierarchical routing which mainly aims to reduce the consumption of sensor nodes energy by assigning different roles to the sensor nodes to create multi-layer scheme for data transmission. This paper embraces a simulation for two known hierarchical routing protocols: Power-Efficient Gathering in Sensor Information Systems (PEGASIS) protocol and an Improved Energy-Efficient PEGASIS-Based (IEEPB) protocol. Both protocols aim to reduce the transmission distance in order to save the nodes energy by performing chainbased clustering. For evaluation, we measured the residual energy and control overhead throughout the network operation time and the results showed major flaws in both protocols such as long link problem and poor leader selection method in PEGASIS. Moreover, high nodes density problem in IEEPB.
\end{abstract}

Copyright $(0) 2019$ Institute of Advanced Engineering and Science. All rights reserved.

\section{Corresponding Author:}

Samah Alnajdi,

Department of Information Technology, Faculty of Computing and Information Technology,

King Abdulaziz University, Jeddah, Kingdom of Saudi Arabia.

Email: salnajdi0003@stu.kau.edu.sa

\section{INTRODUCTION}

A WSN is a network consist of large number of sensor nodes, i.e. tiny and low-cost devices that responsible of collecting data from the deployment area such as temperature, movement, light, sound, ... etc. Moreover, these nodes should collaborate to send their data to more powerful node known as the sink or base station (BS) in order to perform the appropriate actions. However, these kind of networks usually used in tough environments thus it is hard to recharge the sensor nodes [1]. Therefore, one of the principal challenges in WSNs is to reduce the energy consumption by sensors to ensure longer operation time of the networks.

In hierarchical routing protocols (HRPs), the nodes do not send directly to the BS; instead, some nodes are elected to act as higher-level nodes and receive data from the rest of the nodes then send the received data to the BS. Consequently, the transmission distance extremely reduced and the sensor nodes' life is prolonged. There are many routing protocols developed to improve the hierarchical routing process by following different approaches in organizing the roles among the sensor nodes and the nodes' connecting mechanism to set up the routing path. For instance, LEACH protocol [2] which is the first hierarchical protocol to perform clustering as it divides the nodes into number of clusters and in each cluster, one node is elected to be the cluster head that is responsible of sending to the BS. While the communication distance is reduced in LEACH compared to direct routing, the distance between each some cluster heads and the BS will still be long enough to highly consume the sensor's energy. Moreover, the cluster heads are randomly selected regarding their remaining energy, which will affect the robustness and the lifetime of the network. In addition, LEACH perform the clustering in each transmission routing which produce high overhead. Other 
hierarchical known protocol is HEED Protocol [3]. It extends the basic scheme of LEACH by using the residual energy of the node as primary parameter for cluster head selection, and the network topology features such as node degree, distances to neighbors are used as secondary parameters to break the tie between the candidate cluster heads. However, same as LEACH protocol, HEED suffers from high overhead due the repeated clustering process in each round. Moreover, the nodes near the BS will die sooner due huge workload [4].

To overcome some of the main limitations in the previous protocols, new clustering approach were suggested in PEGASIS protocol [5].

\subsection{PEGASIS protocol}

The protocol proposed by Lindsey and Raghavendra in 2002 as the first hierarchical routing protocol to perform chain-based clustering. The goal of their work was to save the sensor nodes energy consumption regardless of the other consequences on the network performance. However, many research have been done to improve the chain-based routing and overcome the deficiencies in PEGASIS protocol such as in [6-11]. One of these improvements was by IEEPB protocol. Table 1 shows a summarization of the charactaristics of some of the recent protocols.

Table 1. Chain-based hierarchical routing protocol

\begin{tabular}{|c|c|c|c|c|c|}
\hline Ref. & Protocol & $\begin{array}{l}\text { Chain formation } \\
\text { method }\end{array}$ & $\begin{array}{l}\text { No. of } \\
\text { chains }\end{array}$ & $\begin{array}{l}\text { Leader node selection } \\
\text { method }\end{array}$ & Proposed method \\
\hline [6] & Hadjila et al. & $\begin{array}{l}\text { the nodes are sorted } \\
\text { based on their } \\
\text { ordinates }\end{array}$ & Multiple & $\begin{array}{l}\text { The closest node to the } \\
\text { chain is the leader node }\end{array}$ & $\begin{array}{l}\text { Form multiple parallel chains in the } \\
\text { direction of the sink. } \\
\text { Form a main chain includes first nodes } \\
\text { of each chain. }\end{array}$ \\
\hline [7] & $\begin{array}{l}\text { Gupta } \\
\text { Saraswat }\end{array}$ & $\begin{array}{l}\text { Greedy algorithm with } \\
\text { the sensor nodes } \\
\text { allowed to opt visited } \\
\text { nodes again if they are } \\
\text { the nearest one from } \\
\text { those sensor }\end{array}$ & Single & $\begin{array}{l}\text { Considers the degree of } \\
\text { nodes in addition to the } \\
\text { residual energy and the } \\
\text { distance to the BS }\end{array}$ & $\begin{array}{l}\text { At the chain formation phase, the end } \\
\text { node connects to its nearest node with } \\
\text { the constraint that it can only connects } \\
\text { to a node closer to the BS. }\end{array}$ \\
\hline [8] & Ruan et al. & $\begin{array}{l}\text { Ant Colony } \\
\text { Optimization [13] }\end{array}$ & Multiple & $\begin{array}{l}\text { Considers the residual } \\
\text { energy of the node and the } \\
\text { distance to the BS. }\end{array}$ & $\begin{array}{l}\text { Uses the neural network to select the } \\
\text { leader nodes. }\end{array}$ \\
\hline [9] & SCBC & $\begin{array}{l}\text { Greedy algorithm } \\
\text { starting by formin two } \\
\text { chains at once that } \\
\text { later connected } \\
\text { together. }\end{array}$ & Multiple & $\begin{array}{l}\text { Considers the residual } \\
\text { energy and cost function. } \\
\text { Secondary leader nodes } \\
\text { are selected to send to the } \\
\text { BS. }\end{array}$ & $\begin{array}{l}\text { Divide the sensing are into sectors to } \\
\text { form multiple chains. In order to reduce } \\
\text { the delay accoused by long chains. }\end{array}$ \\
\hline [10] & Ghosh et al. & $\begin{array}{l}\text { Ant Colony } \\
\text { Optimization [13] }\end{array}$ & Single & $\begin{array}{l}\text { Considers both the } \\
\text { residual energy of the } \\
\text { node and the distance to } \\
\text { BS }\end{array}$ & $\begin{array}{l}\text { Distributed Dominating Set Formation } \\
\text { (DDSF) to choose the action nodes, the } \\
\text { rest will be in a sleep mode. }\end{array}$ \\
\hline [11] & Jawad and Ali & Greedy algorithm & Multiple & $\begin{array}{l}\text { Considers both the } \\
\text { residual energy of the } \\
\text { node and the distance to } \\
\text { BS }\end{array}$ & $\begin{array}{l}\text { Proposed using the k-means clustering } \\
\text { algorithm to divide the nodes. }\end{array}$ \\
\hline$[12]$ & IEEPB & $\begin{array}{l}\text { Advanced greedy } \\
\text { algorithm }\end{array}$ & Single & $\begin{array}{l}\text { Considers both the } \\
\text { residual energy of the } \\
\text { node and the distance to } \\
\text { the BS. }\end{array}$ & $\begin{array}{l}\text { Proposed an additional step to the } \\
\text { greedy algorithm to reduce the distance } \\
\text { between the connected nodes. }\end{array}$ \\
\hline [13] & CHIRON & Greedy algorithm & Multiple & $\begin{array}{l}\text { Considers the residual } \\
\text { energy only. }\end{array}$ & $\begin{array}{l}\text { Proposed dividing the sensing area into } \\
\text { leavels where the BS is the centeral } \\
\text { point. }\end{array}$ \\
\hline$[14]$ & Shekh et al. & Greedy algorithm & Multiple & $\begin{array}{l}\text { Considers the nodes } \\
\text { density in addition to the } \\
\text { residual energy and } \\
\text { distance from the BS }\end{array}$ & $\begin{array}{l}\text { Proposed dividng the sensing moreover } \\
\text { than CHIRON protocol by dividng each } \\
\text { leavel into equal sizs groups to have } \\
\text { more similar in length chains. }\end{array}$ \\
\hline$[15]$ & $\begin{array}{l}\text { Patel and } \\
\text { Munjani }\end{array}$ & Greedy algorithm & Multiple & $\begin{array}{l}\text { In turn. All the alive } \\
\text { nodes have equal chance } \\
\text { to be the leader node. }\end{array}$ & $\begin{array}{l}\text { Proposed multi-chain PEGASIS where } \\
\text { the only deffiernce from pegasis is the } \\
\text { sensing area is divided into four regions }\end{array}$ \\
\hline$[16]$ & $\begin{array}{l}\text { Bhatti and } \\
\text { Raina }\end{array}$ & $\begin{array}{l}\text { Modified Greedy } \\
\text { algorithm with fuzzy } \\
\text { system }\end{array}$ & Single & Same as PEGASIS & $\begin{array}{l}\text { Modifys the PEGASIS protocol using } \\
\text { fuzzy system and cuckoo search } \\
\text { algorithm for optimization }\end{array}$ \\
\hline [17] & PEGASIS-INL & Greedy algorithm & Single & $\begin{array}{l}\text { Based on the measured } \\
\text { RSSI value }\end{array}$ & $\begin{array}{l}\text { A subset of the nodes selected to be } \\
\text { candidate leaders and multiple- } \\
\text { overlapped chains formed with the } \\
\text { candidate leaders as root. }\end{array}$ \\
\hline
\end{tabular}




\begin{tabular}{|c|c|c|c|c|c|}
\hline$[18]$ & PEG-BBO & $\begin{array}{l}\text { Biogeography-Based } \\
\text { Optimization }\end{array}$ & Single & $\mathrm{x}$ & $\begin{array}{l}\text { Proposed BBO that is a population } \\
\text { based global optimization technique } \\
\text { developed on the basis of the science of } \\
\text { biogeography to result in better route } \\
\text { chain. }\end{array}$ \\
\hline [19] & Hop PEGASIS & Greedy algorithm & Multiple & $\mathrm{x}$ & $\begin{array}{l}\text { The protocol divides the nodes into } \\
\text { clusters and then apply the hierarchical } \\
\text { PEGASIS on the cluster leaders to } \\
\text { avoid long distance between the leaders } \\
\text { and between the leaders and the BS }\end{array}$ \\
\hline [20] & PEGASIS-E & $\begin{array}{l}\text { New method based on } \\
\text { the average distance of } \\
\text { all alive nodes }\end{array}$ & Single & Same as PEGASIS & $\begin{array}{l}\text { Proposed using average distance among } \\
\text { the sensor nodes as the criteria for } \\
\text { chaining. All the nodes in the radio } \\
\text { range will connect to the same end } \\
\text { node. }\end{array}$ \\
\hline [21] & MIEEPB & Greedy algorithm & Multiple & $\begin{array}{l}\text { Considers both the } \\
\text { residual energy of the } \\
\text { node and the distance to } \\
\text { the BS. }\end{array}$ & $\begin{array}{l}\text { Developed an algorithm for path of } \\
\text { mobile sink as they proposed a mobile } \\
\text { sink that moves along its path and stays } \\
\text { temporarly at temporary } \\
\text { location for data collection }\end{array}$ \\
\hline [22] & IECBSN & $\begin{array}{l}\text { Starting from the node } \\
\text { closest to the BS and } \\
\text { connect to their } \\
\text { nearest node, the } \\
\text { process stops if the } \\
\text { chain selected length } \\
\text { is reached }\end{array}$ & Multiple & $\begin{array}{l}\text { Considers both the } \\
\text { residual energy of the } \\
\text { node and the distance to } \\
\text { the BS. }\end{array}$ & $\begin{array}{l}\text { Proposed forming multiple chains } P \text {, } \\
\text { where } P \text { equals } N / M \text { as } N \text { the initial } \\
\text { number of nodes and } M \text { the chains } \\
\text { length. }\end{array}$ \\
\hline [23] & Lim and Park & $\begin{array}{l}\text { Efficient } \\
\text { Formation } \\
\text { algorithm }\end{array}$ & Single & Same as PEGASIS & $\begin{array}{l}\text { Proposed using strip tree geometry and } \\
\text { in-order tree traversal algorithms for } \\
\text { chain formation phase }\end{array}$ \\
\hline
\end{tabular}

\subsection{IEEPB protocol}

An Improved Energy-Efficient PEGASIS-Based Protocol (IEEPB) is proposed by Feng et al. in 2011 [12]. The protocol main contribution is modifying the chain forming algorithm to farther minimize the transmission energy consumption. Although the results in [12] showed an improved performance of IEEPB, we wanted to test the protocol performance under several scenarios in comparison with PEGASIS.

The next section will discuss the methods used in the chain formation phase for the PEGASIS protocol and for IEEPB protocol, followed by the leader node selection methods in section III. To compare the performance, Section IV presents the simulation environment and the results. Finally, a discussion and analysis of the results provided in Section V and the conclusion in Section VI.

\section{RESEARCH METHOD}

\subsection{Chain Formation Methods}

In this stage of the chain-based protocols, nodes are set to form a chain-like topology between them; therefore, when the data transmission phase comes each node will send its sensed and aggregated data to their neighbor node in the chain, in the direction of the leader node of the chain. Many algorithms proposed to perform the chain formation phase in the chain-based protocols and the process could be centralized, i.e. processed at the BS, or distributed, i.e. processed by the nodes themselves through communication among them.

\subsubsection{PEGASIS protocol}

In PEGASIS, they follow the greedy approach in the chain formation process where each node connects to its nearest node that did not join the chain yet. The chain formation starts from the farthest node from the BS, in order to make sure that nodes far from the BS have close neighbors, since the neighbor distance in the greedy approach will increase gradually as more nodes join the chain and less nodes left available to connect. Figure 1 shows a chain of 200 nodes formed using the greedy algorithm as in PEGASIS protocol. In case of a node dies, the whole chain is reformed again in the same manner. 


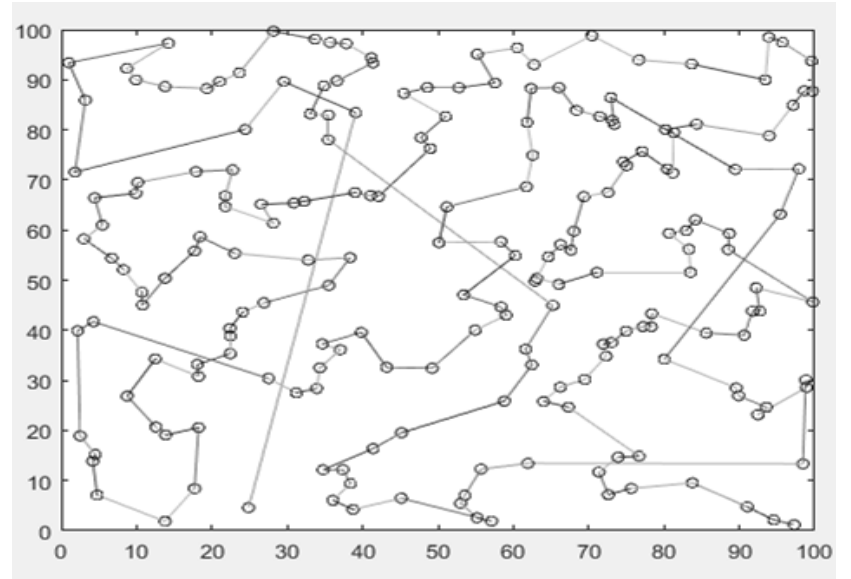

Figure 1. PEGASIS Protocol Network

\subsubsection{IEEPB protocol}

An enhanced greedy algorithm for the chain formation process was adopted in IEEPB, where the comparison of distance occurs twice before any node join the chain. The chain formed by the enhanced algorithm as follow:

1. The node farthest from the BS join the chain first and labeled as the end node of the chain

2. End node of the chain finds the nearest node that did not join the chain yet and sets it as next node waiting to join the chain.

3. Next node compare distance from itself to nodes already on the chain and connects with the nearest node of them.

4. After joining the chain, the next node becomes the end node of the chain and steps 2-4 repeated until all nodes join the chain.

Similar to PEGASIS, in case of a node dies the whole chain is reformed again in order to bypass the dead node. Figure 2 shows a chain of 200 nodes formed using the enhanced greedy algorithm as in IEEPB protocol.

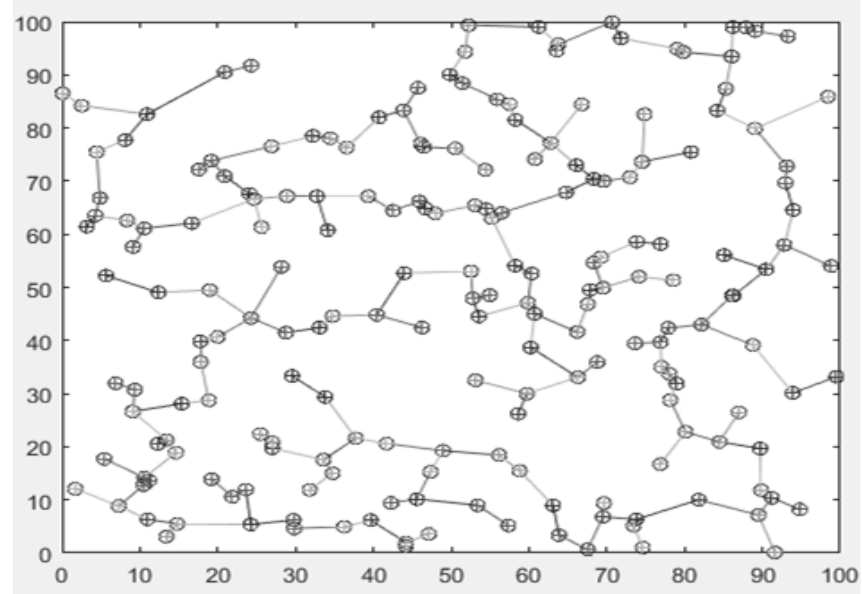

Figure 2. IEEPB Protocol Network

\subsection{Leader Selection Method}

The leader node in HRP is the node responsible of forwarding the received data to the BS. Therefore, choosing the most fitting node to be a leader node is an important step: 


\subsubsection{PEGASIS protocol}

Nodes in PEGASIS take turns to be the leader of the round. In round $\mathrm{i}$, the node number $\mathrm{i}$ mod $\mathrm{N}$ is the leader, where $\mathrm{N}$ is total number of nodes. There is no consideration of how far the node located from the BS nor any other parameter; all nodes will have equal chance to become a leader node.

\subsubsection{IEEPB protocol}

For more suitable leader selection, the IEEPB uses weighting method that considers both the residual energy of the node and its distance from BS as parameters. In each round, the combined weight of each node is compared and the node with minimum weight, i.e. the less costly to be the leader of the round is selected as the leader node of the round.

\section{RESULTS AND ANALYSIS}

\subsection{Simulation Environment}

The simulation of both protocols done using MATLAB 2017a [24] where $N$ sensor nodes randomly distributed on a square sensing field with the BS fixed far from the sensing field.

\subsection{Energy Model}

The same radio model described in [25] is adopted in this simulation. In this model, to transmit an L bit message for a distance $\mathrm{d}$, the radio expends:

$$
E_{T}(L, d)=E_{\text {elec }} \times L+E_{\text {amp }} \times L \times d^{n}
$$

to receive an $L$ bit message, in the model the radio expends:

$$
E_{R}(L)=E_{\text {elec }} \times L
$$

Where $\mathrm{E}_{\text {elec }}$ is the energy dissipated per bit to run the transmitter or the receiver circuits and the $\mathrm{E}_{a m p}$ is the energy dissipation of the transmission amplifier depending on the distance to the receiver. In equation 1 , if the distance between transmitter node and receiver node is less than a threshold distance then the free space channel model is used where $\left(n=2, E_{a m p}=E_{f s}\right)$; otherwise multipath fading channel model is used where $\left(n=4, E_{a m p}=E_{m p}\right)$. Table 2 presents the network parameters used in simulation of both protocols.

Table 2. Simulation parameters

\begin{tabular}{cc}
\hline Parameter & Value \\
\hline Number of nodes $(N)$ & 200 and 400 \\
Network size & $100 \mathrm{~m} * 100 \mathrm{~m}$ \\
BS location & $(50,175)$ \\
Initial energy & $0.5 \mathrm{~J}$ \\
$E_{\text {elec }}$ & $50 \mathrm{~nJ} / \mathrm{bit}$ \\
$E_{f s}$ & $100 \mathrm{pJ} / \mathrm{bit} / \mathrm{m} 2$ \\
$E_{m p}$ & $0.0013 \mathrm{pJ} / \mathrm{bit} / \mathrm{m} 4$ \\
The threshold distance & $\sqrt{\left(\mathrm{E}_{\mathrm{fs}} \mathrm{E}_{\mathrm{mp}}\right)}$ \\
Data packet size & $2000 \mathrm{bit}$ \\
Energy of data aggregation EDA & $5 \mathrm{~nJ} / \mathrm{bit}$ \\
\hline
\end{tabular}

\subsection{Results of Simulation}

The results are average of at least five simulation times. Figure 3 shows the network lifetime of 200 nodes by presenting the number of alive nodes from first round until last node dies. In PEGASIS, the average round the first node dies was round 548 while in IEEPB is round 1160 with 53\% improvement. Moreover, the network dies at average 1633 rounds in PEGASIS and at 1831 rounds in IEEPB with $11 \%$ improvement. In addition, Figure 4 shows the total residual energy of all nodes throughout the network lifetime.

Same pervious performance metrics applied on 400 nodes network and results in as Figures 5 and 6 that shows PEGASIS protocol giving similar performance as in 200 network while the performance decreased clearly with IEEPB protocol.

In Figure 5, the 53\% improvement in the average round the first node dies in IEEPB over PEGASIS decreased to $34 \%$ and the whole network dies with $6 \%$ improvement over PEGASIS instead of $11 \%$ as in with 200 nodes network. Moreover, Figure 6 shows IEEPB protocol residual energy freely dropping around the round 1400 . 


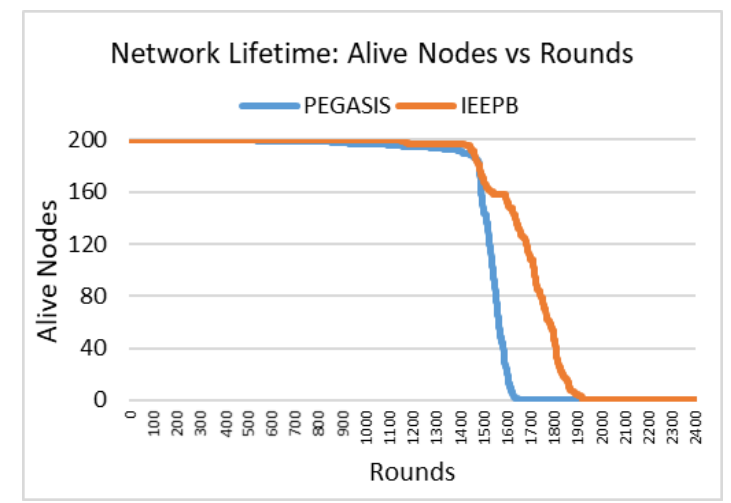

Figure 3. Lifetime of 200 Nodes Network

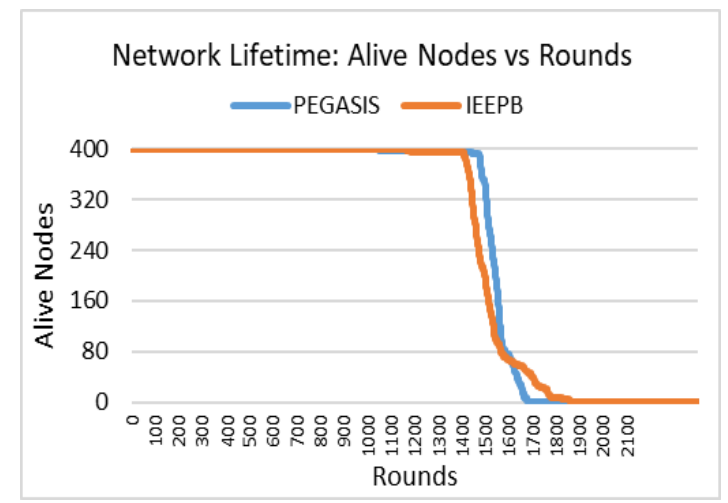

Figure 5. Lifetime of 400 Nodes Network

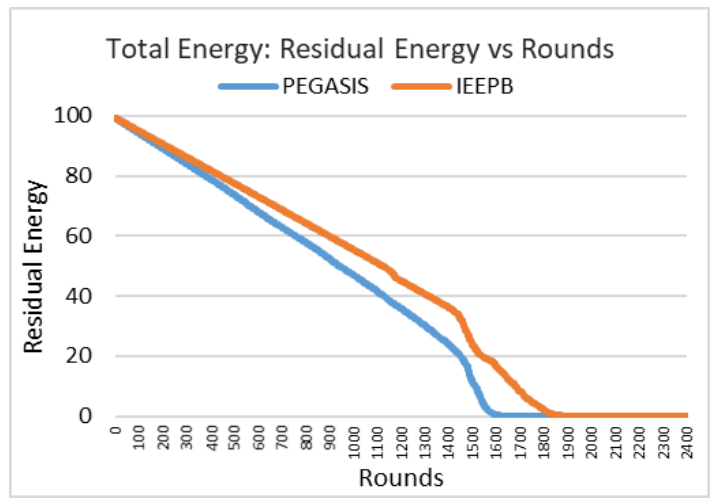

Figure 4. Residual Energy of 200 Nodes Network

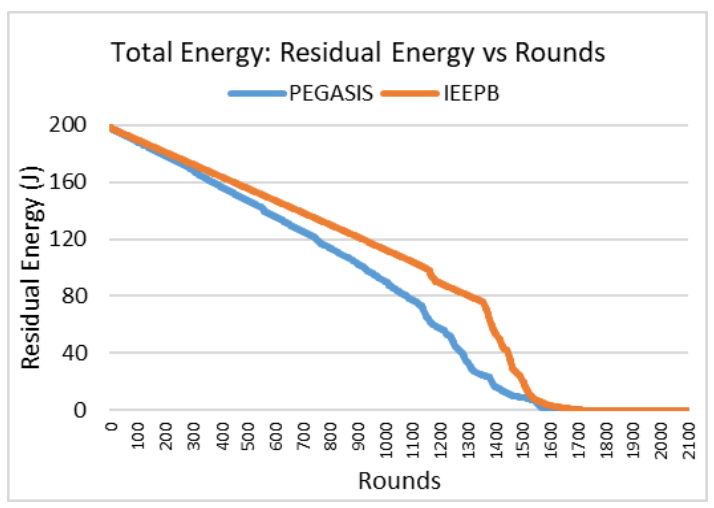

Figure 6. Residual Energy of 400 Nodes Network

Another metric we considered is the overhead. We measured the total number of control packets exchanged between the sensor nodes and the BS to set up the routing path including chain formation and reformations throughout the network lifetime. Figure 7 shows the overhead for both 200 and 400 nodes networks.

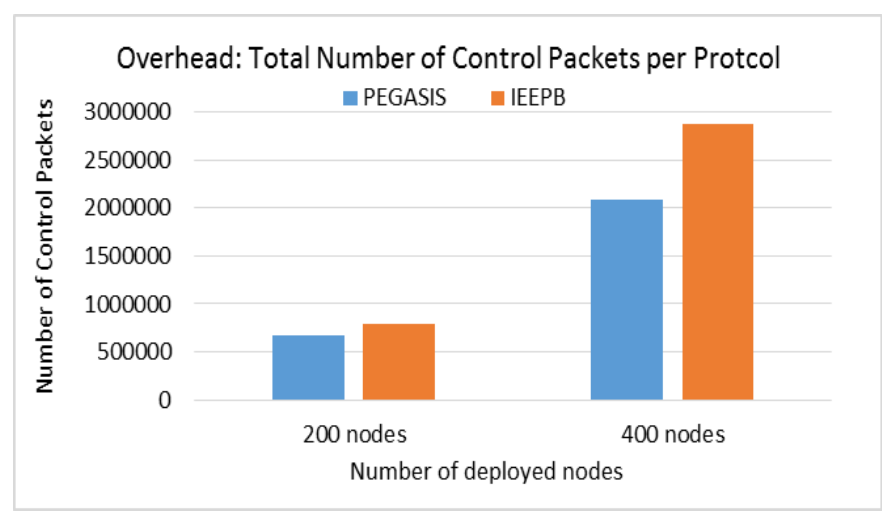

Figure 7. Control Overhead

\subsection{Analysis of Results}

In general, the greedy algorithm used in PEGASIS causes long link (LL) problem in the chain, as shown in Figure 1, because of the last nodes joining the chain will have fewer choices to connect to, since nodes in greedy approach cannot be revisited. However, in the enhanced greedy algorithm in IEEPB nodes 
can be revisited, i.e. nodes are allowed to have more than two connections, as shown in Figure 2, which solved the LL problem in PEGASIS. Therefore, solving the LL problem means larger sending distance between nodes are avoided which improved the energy consumption of the nodes compared to the greedy algorithm.

Based on our experiments of different networks sizes simulation, the avoidance of LL problem showed obvious improvement in performance of networks with less nodes density, as in Figure 3 with 200 nodes; however, as the density of nodes increased the avoiding of LL problem was not enough for IEEPB to give better performance than PEGASIS. For instance, Figure 5 shows the lifetime of 400 nodes network in the same $100 * 100 \mathrm{~m}$ sensing area and IEEPB performance clearly decreased compared to Figure 3 . In addition, at some point in Figure 5 when more than 80 nodes were alive, the total number of alive nodes in PEGASIS protocol was more than IEEPB protocol.

This fell in IEEPB performance is due the increase of the probability of a node to have more connected nodes (child node) as the number of nodes in area increase. Therefore, the energy consumption of each node will be larger in IEEPB since nodes consume $\mathrm{E}_{\mathrm{R}}(L)$ per every child node while in PEGASIS each node has only one child node to receive data from. This problem could be solved by forcing a constraint on the number of connected nodes, or by decreasing the density of nodes by having multiple chains in a network instead of single chain.

In this paper, we assumed a distributed chain formation process; therefore, nodes have to communicate by exchanging control packets in order to form the chain. In Figure 7, the results show that PEGASIS has total number of control packets less than IEEPB; this is due the greedy algorithm in PEGASIS requiring less communications for a node to join the chain in comparison of the enhanced greedy algorithm in IEEPB.

Moreover, the overhead caused by the enhanced greedy algorithm increase as the number of nodes involved in a chain formation process increase, therefore, reducing the overhead could achieved by having multiple $K$ chains as the communication will minimize $K$ times ( $K$ is number of chains).

\section{CONCLUSION}

In conclusion, the enhanced greedy algorithm used by IEEPB protocol solved the LL problem caused by the greedy algorithm in PEGASIS, therefore, the energy consumption for data transmission is reduced. Moreover, the consideration of residual energy and distance from the BS in IEEPB improved the energy consumption as well. However, the simulation results showed a fallback in IEEPB performance including the network lifetime, energy consumption, and total overhead, as the nodes the number of deployed increases, i.e. higher density. Therefore, a discussion of possible solutions of the problem is presented. Our future work will focus on improving the IEEPB protocol and solve the limitations in case of a high-density network.

\section{ACKNOWLEDGEMENTS}

This project was funded by King Abdulaziz City for Science and Technology (KACST), under grant number 0017-009-02-17-1. The authors, therefore, acknowledge with thanks KACST for technical and financial support.

\section{REFERENCES}

[1] H. Marhoon, et al., "Chain-based routing protocols in wireless sensor networks: A survey," ARPN J. Eng. Appl. Sci., vol. 10, pp. 1389-1398, 2015.

[2] W. R. Heinzelman, et al., "Energy-Efficient Communication Protocol for Wireless Microsensor Networks," Proceedings of the 33rd Hawaii International Conference on System Sciences, Washington, DC, USA, vol. 8, pp. $8020,2000$.

[3] O. Younis and S. Fahmy, "HEED: a hybrid, energy-efficient, distributed clustering approach for ad hoc sensor networks," IEEE Trans. Mob. Comput., vol. 3, pp. 366-379, 2004.

[4] R. Chaudhary, "Review Paper on Energy- Efficient Protocols in Wireless Sensor Networks," IOSR J. Eng., vol. 4, pp. 01-07, 2014.

[5] S. Lindsey and C. S. Raghavendra, "PEGASIS: Power-efficient gathering in sensor information systems," Proceedings, IEEE Aerospace Conference, vol. 3, pp. 3-1125-3-1130, 2002.

[6] M. Hadjila, et al., "A Chain-Based Routing Protocol to Maximize the Lifetime of Wireless Sensor Networks," vol. 2013, 2013.

[7] M. Gupta and L. Saraswat, "Energy aware data collection in wireless sensor network using chain based PEGASIS," International Conference on Recent Advances and Innovations in Engineering (ICRAIE-2014), pp. 1-5, 2014.

[8] T. Li, et al., "An Improved PEGASIS Protocol for Wireless Sensor Network," 2015 3rd International Conference on Computer and Computing Science (COMCOMS), pp. 16-19, 2015. 
[9] N. D. Tan and N. D. Viet, "SCBC: Sector-chain based clustering routing protocol for energy efficiency in heterogeneous wireless sensor network," 2015 International Conference on Advanced Technologies for Communications (ATC), pp. 314-319, 2015.

[10] S. Ghosh, et al., "Enhanced PEGASIS using ant colony optimization for data gathering in WSN," 2016 International Conference on Information Communication and Embedded Systems (ICICES), pp. 1-6, 2016.

[11] T. M. Jawad and N. A. Ali, "Using K-means clustering algorithm with Power Efficient Gathering in Sensor Information Systems Protocol," IJCSET, vol. 6, pp. 5, 2016.

[12] S. Feng, et al., "An improved Energy-Efficient PEGASIS-Based protocol in Wireless Sensor Networks," 2011 Eighth International Conference on Fuzzy Systems and Knowledge Discovery (FSKD), vol. 4, pp. 2230-2233, 2011.

[13] M. Dorigo and M. Birattari, "Ant Colony Optimization," Encyclopedia of Machine Learning, C. Sammut and G. I. Webb, Eds. Boston, MA: Springer US, pp. 36-39, 2010.

[14] M. F. Shekh, et al., "Improved energy-efficient chain-based routing protocol for edge-based wireless sensor networks," 2016 International Conference on Communication and Signal Processing (ICCSP), pp. 2225-2231, 2016.

[15] B. Patel and J. Munjani, “Chain based Routing Protocol for Wireless Sensor Network,” Int. J. Comput. Appl., vol. 134, pp. 21-24, 2016.

[16] G. K. Bhatti and J. P. S. Raina, "Cuckoo based Energy Effective Routing in Wireless Sensor Network," vol. 3, pp. 4, 2014.

[17] A. K. Mishra, et al., "An enhancement of PEGASIS protocol with improved network lifetime for Wireless Sensor Networks," 2015 IEEE Power, Communication and Information Technology Conference (PCITC), pp. 142-147, 2015.

[18] B. Singh and E. S. Kaur, "An Improved Energy-Efficient BBO-Based PEGASIS Protocol in Wireless Sensors Network," vol. 4, pp. 5, 2014.

[19] M. A. Ali and A. K. Rajpoot, "Development of energy efficient routing protocol using Hop PEGASIS in Wireless Sensor Networks," 2014.

[20] V. Nehra and A. K. Sharma, "PEGASIS-E: Power Efficient Gathering in Sensor Information System Extended," pp. 5, 2013.

[21] M. R. Jafri, et al., "Maximizing the Lifetime of Multi-chain PEGASIS using Sink Mobility," ArXiv13034347 Cs, 2013.

[22] S. Mahajan, et al., "Improved Enhanced Chain Based Energy Efficient Wireless Sensor Network," 2013.

[23] S. J. Lim and M. S. Park, "Energy-Efficient Chain Formation Algorithm for Data Gathering in Wireless Sensor Networks," Int. J. Distrib. Sens. Netw., vol. 8, pp. 843413, 2012.

[24] "MATLAB - MathWorks," 2019. Available: https://www.mathworks.com/products/matlab.html.

[25] W. B. Heinzelman, et al., "An application-specific protocol architecture for wireless microsensor networks," IEEE Trans. Wirel. Commun., vol. 1, pp. 660-670, 2002. 